\title{
Optimized Synthesis of FeS Nanoparticles with a High Cr(VI) Removal Capability
}

\author{
Yuanyuan Liu, ${ }^{1}$ Wenyan Xiao, ${ }^{1}$ Jiajia Wang, ${ }^{1,2}$ Zakaria A. Mirza, ${ }^{3}$ and Tao Wang ${ }^{1}$ \\ ${ }^{1}$ Key Laboratory of the Three Gorges Reservoir Region's Eco-Environment of Ministry of Education, Chongqing University, \\ Chongqing 400044, China \\ ${ }^{2}$ Chengdu Institute of Planning \& Design, Chengdu, Sichuan 610041, China \\ ${ }^{3}$ Chongqing Institute of Green and Intelligent Technology, Chinese Academy of Sciences, Chongqing 400714, China
}

Correspondence should be addressed to Yuanyuan Liu; liuyuanyuan@cqu.edu.cn

Received 3 November 2015; Revised 12 January 2016; Accepted 20 January 2016

Academic Editor: Jae-Min Myoung

Copyright (C) 2016 Yuanyuan Liu et al. This is an open access article distributed under the Creative Commons Attribution License, which permits unrestricted use, distribution, and reproduction in any medium, provided the original work is properly cited.

FeS nanoparticles were synthesized using chemical precipitation method involving sulfide and ferrous solutions. Effects of important synthesis parameters including stabilizer, time taken for titration, horizontal oscillation speed, and initial salt concentration on the size of synthesized FeS nanoparticles were investigated by Orthogonal Array design. Increasing the CMC dosage significantly made the hydrodynamic diameter decrease between $0.05 \mathrm{wt} . \%$ and $0.15 \mathrm{wt} . \%$ while $\mathrm{Na}_{2} \mathrm{~S}$ titration, oscillation rate, and $\mathrm{Na}_{2} \mathrm{~S}$ concentration did not show significant influence on the hydrodynamic diameter of FeS nanoparticles. The synthesized FeS nanoparticles were characterized by using XRD (X-ray diffraction), TEM (transmission electron microscopy), and XPS (X-ray photoelectron spectroscopy). The as-synthesized FeS nanoparticles had an average size of $25 \pm 10 \mathrm{~nm}$ and had a better long-term stability after storage for 150 days compared to bare FeS particles. Because of the optimized process parameters, the synthesized FeS nanoparticles had a higher $\mathrm{Cr}(\mathrm{VI})$ removal capacity of $683 \mathrm{mg}$ per gram of FeS in comparison to the previously reported cases, and up to $92.48 \% \mathrm{Cr}(\mathrm{VI})$ was removed from aqueous solutions. The small size, special surface property, and high reactivity make the synthesized FeS nanoparticles a promising tool for the remediation of $\mathrm{Cr}(\mathrm{VI})$ contaminated soil and groundwater.

\section{Introduction}

Nanomaterials have become one of the most promising materials to solve different problems in the various demanding fields [1-5]; in particular sulfur containing nanomaterials have been applied extensively in dechlorination of tetrachloroethene [6], cathode material for lithium batteries [7], catalytic applications [8], electrochemical DNA detection analysis [9], and so on. The successful synthesis and utilization of nanoscale metal sulfides have been accomplished such as CdS $\backslash \mathrm{ZnS} \backslash \mathrm{FeS} \backslash \mathrm{CuS}$ [10-13]. The size, shape, and other properties of those metal sulfide nanomaterials, which determined their applications, were greatly influenced by the synthesis methods and conditions [14-16].

FeS nanotubes [17], FeS nanosheets [18, 19], and Fe/FeS nanoparticles [20] are synthesized with various methods such as sulfurization of hematite, solvothermal synthesis, soft-template method, and chemical reduction. During these processes, the frequent usage of toxic gases $\left(\mathrm{H}_{2} \mathrm{~S}\right)$, complicated reactions, and unsafe reagents restricts their selection. Jeong et al. [13] produced nanosize mackinawite simply by mixing $\mathrm{Na}_{2} \mathrm{~S}$ solution with $\mathrm{FeCl}_{2}$ solution with an excess of sulfide, while FeS particles aggregated easily during sample drying process. Gong et al. [21] prepared FeS nanoparticle suspensions with CMC (Carboxymethyl Cellulose) as a stabilizer to efficiently immobilize $\mathrm{Hg}^{2+}$ cation in water solution, and it was found that the size of FeS nanoparticles is an important factor related to the efficiency of chemical reaction or adsorption during their remediation process. In addition, the long-term stability of the nanoparticles may influence the effectiveness of their utilization as a remediation reagent; however the specific knowledge on how the synthesis process 
influences the size and the long-term stability of FeS nanoparticles is lacking and material's potential has not been realized.

Chromium is one of the notorious heavy mental contaminants in groundwater, surface water, and soil, and hexavalent chromium is the chemical form with the highest toxicity and mobility relative to other forms in different geological environments [22]. It is hard to achieve an efficient remediation for $\mathrm{Cr}(\mathrm{VI})$ in groundwater and soil through traditional treatments. Reactive FeS solid is an excellent reductant with a strong adsorption capacity, which has been used to remove both metals and organics from groundwater [23]. CMC stabilized FeS nanoparticles [24] and nanosized composites $\mathrm{C} / \mathrm{FeS} / \mathrm{Fe}$ [25] displayed an excellent $\mathrm{Cr}(\mathrm{VI})$ removal performance when applying to treat contaminated water. Nanoscale FeS may have a greater remediation potential in the $\mathrm{Cr}(\mathrm{VI})$ contaminated environment, such as soil or groundwater.

Herein, we attempted to find out the key factors during the synthesis of FeS nanoparticles and optimized the synthesis procedures to accomplish a higher $\mathrm{Cr}(\mathrm{VI})$ removal efficiency. The specific objectives of this study were to (1) identify the significant factors and optimize the synthesis conditions to obtain nanoparticles with a smaller size in order to increase their remediation efficiency; (2) examine the long-term stability of FeS nanoparticles in various conditions; and (3) test the effectiveness of the stabilized CMC-FeS nanoparticles for removal of $\mathrm{Cr}$ (VI) from water solutions.

\section{Materials and Methods}

2.1. Chemicals and Materials. All the chemicals used in this study were of analytical or higher grade except for CMC (M.W. $=300-800$ in sodium salt) which was purchased from Shanghai Qiangshun Chemical Reagent Co., Ltd. Iron(II) sulfate heptahydrate $\left(\mathrm{FeSO}_{4} \cdot 7 \mathrm{H}_{2} \mathrm{O}\right)$ was purchased from Sinopharm Chemical Reagent Co., Ltd. Sodium sulfide nonahydrate $\left(\mathrm{Na}_{2} \mathrm{~S} \cdot 9 \mathrm{H}_{2} \mathrm{O}\right)$ and potassium dichromate $\left(\mathrm{K}_{2} \mathrm{Cr}_{2} \mathrm{O}_{4}\right)$ were obtained from Chengdu Kelong Chemical Reagent Factory.

2.2. Synthesis of FeS Nanoparticles. The synthesis procedure of FeS nanoparticles in Figure 1 was adapted from Xiong's method [26], by which FeS nanoparticles were prepared using $\mathrm{CMC}$ as a stabilizer. CMC solutions $(110 \mathrm{~mL})$ with certain concentrations (0.05 wt.\%, 0.1 wt. \%, or 0.2 wt.\%) were mixed with $\mathrm{FeSO}_{4}$ aqueous solution $(20 \mathrm{~mL})$ in a $500 \mathrm{~mL}$ flask on a horizontal oscillator. Then $\mathrm{Na}_{2} \mathrm{~S}$ solution $(20 \mathrm{~mL})$ with a concentration of $0.0213,0.0426$, or $0.0639 \mathrm{M}$ was added to $\mathrm{Fe}^{2+}$-CMC solution through a constant flow pump and then oscillated continuously with certain rates $(100,200$, or $250 \mathrm{rpm}$ ) for $5 \mathrm{~min}$. The concentration of FeS nanoparticles was kept at $500 \mathrm{mg} / \mathrm{L}$ as a suspension. For comparison, bare FeS solution was also prepared following the same procedure without addition of a stabilizer. During the preparation, the whole system was deoxygenated by bubbling nitrogen gas (99.99\% pure) at a flow rate of $5 \mathrm{~L} / \mathrm{min}$.

Stabilizer, time taken for titration, horizontal oscillation speed, and initial salt concentration were selected as the input factors in 3-level orthogonal tests in order to screen the key factors and optimize the synthesis conditions, and the ranges

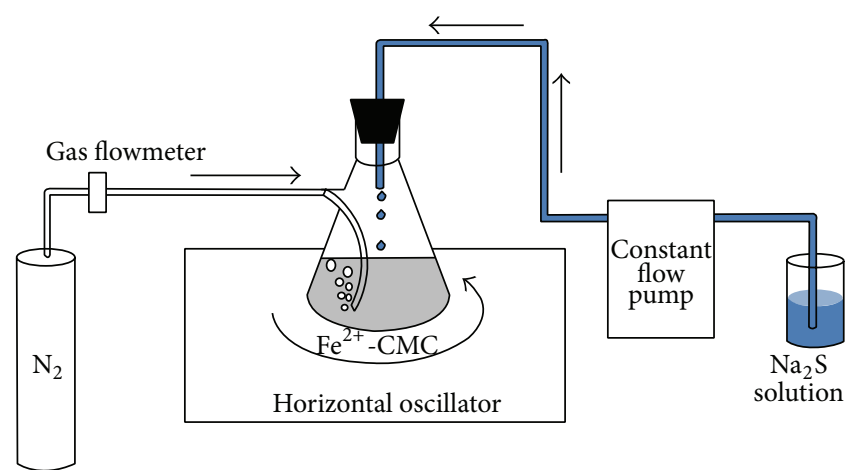

FIGURE 1: Schematic of FeS nanoparticles synthesis.

of the parameters were determined based on the practical conditions, preliminary test results, and previous studies as shown in Table 1 . The hydrodynamic diameter of the synthesized FeS nanoparticles was deployed to evaluate the various combinations of the process conditions to obtain the optimal parameters for the synthesis. The process parameters of FeS nanoparticles were studied through an $\mathrm{OA}_{9}\left(3^{4}\right)$ Orthogonal Array design as reported in Table 1.

\subsection{Characterization of the Synthesized FeS Nanoparticles.} The morphology of the FeS particles was obtained using a TECNAI20TEM from FEI Company operated at $200 \mathrm{kV}$. Samples for TEM (transmission electron microscopy) were prepared by placing a droplet of dilute dispersed suspension on a carbon coated 200-mesh Cu TEM grid followed by vacuum drying. XRD (X-ray diffraction) analysis of synthesized nano-FeS was carried out using Jindao-7000 with $\mathrm{Cu}-\mathrm{K} \alpha$ radiation and the angle $2 \theta$ was measured between $3^{\circ}$ and $80^{\circ}$ in a step interval of $0.02^{\circ}$ with a scan rate of $2^{\circ} / \mathrm{min}$. The XRD patterns were processed using MDI Jade 6.5 software loaded with ICDD database (Materials Data Inc., Livermore, CA, USA). The elemental and species analysis of FeS nanoparticles was carried out by using a Thermo ESCALAB 250 Xray photoelectron spectrometer and monochromatic Al-K $\alpha$ $(h v=1486.6 \mathrm{eV})$ radiation. All the peak positions for analysis were calibrated using C1s peak at $284.5 \mathrm{eV}$.

2.4. Removal of Cr(VI) by the FeS Nanoparticles and Analysis. Removal of $\mathrm{Cr}(\mathrm{VI})$ by synthesized FeS nanoparticles was conducted in $500 \mathrm{~mL}$ erlenmeyer flasks. Typically, bare FeS, synthesized FeS (0.05 wt.\% CMC), and FeS (0.15 wt.\% CMC) were added to each flask, respectively. Subsequently, $\mathrm{Cr}$ (VI) solutions with various concentrations were added to maintain an FeS-to-Cr(VI) molar ratio of 0.8 . The final volume of the reaction system was $200 \mathrm{~mL}$ with an $\mathrm{FeS}$ concentration of $67.7 \mathrm{mg} / \mathrm{L}$. The $\mathrm{pH}$ of the solution was kept at 5.6 with MES (4morpholineethanesulfonic acid) and $\mathrm{NaOH}$ buffer solutions.

The flasks were sealed and agitated on a horizontal oscillator at $250 \mathrm{rpm}$ and temperature of $25 \pm 1^{\circ} \mathrm{C}$. Samples were withdrawn at scheduled intervals $(1,5,15,40,90$, and $150 \mathrm{~min})$ to determine the aqueous concentrations of chromium. The FeS nanoparticles, solids, and aqueous solutions after reactions were collected by filtering the suspensions using a $25 \mathrm{~nm}$ 
TABLE 1: $\mathrm{OA}_{9}\left(3^{4}\right)$ matrix for parameter optimization in the synthesis of FeS nanoparticles and DLS particle sizes (hydrodynamic diameter).

\begin{tabular}{lccccc}
\hline \multirow{2}{*}{ Run number } & & \multicolumn{2}{c}{ Factor } & & Hydrodynamic diameter $(\mathrm{nm})$ \\
\hline 1 & $\mathrm{CMC}(\mathrm{w} / \mathrm{w})$ & Oscillation $(\mathrm{rpm})$ & Titration $(\mathrm{mL} / \mathrm{s})$ & $\mathrm{Na}_{2} \mathrm{~S}(\mathrm{M})$ & 186.9 \\
2 & $0.05 \%$ & 200 & 0.05 & 0.0426 & 258.8 \\
3 & $0.05 \%$ & 100 & 0.01 & 0.0213 & 139.2 \\
4 & $0.05 \%$ & 250 & 0.15 & 0.0639 & 171.5 \\
5 & $0.1 \%$ & 100 & 0.05 & 0.0639 & 151.3 \\
6 & $0.1 \%$ & 250 & 0.01 & 0.0426 & 47.39 \\
7 & $0.1 \%$ & 200 & 0.15 & 0.0213 & 25.84 \\
8 & $0.2 \%$ & 250 & 0.05 & 0.0213 & 127.4 \\
9 & $0.2 \%$ & 200 & 0.01 & 0.0639 & 108.5 \\
\hline
\end{tabular}

TABLE 2: ANOVA results for the synthesis of FeS nanoparticles using $\mathrm{OA}_{9}\left(3^{4}\right)$ matrix.

\begin{tabular}{|c|c|c|c|c|}
\hline Level & A (stabilizer) & $\mathrm{B}$ (oscillation) & $\mathrm{C}$ (titration) & $\mathrm{D}\left(\mathrm{Na}_{2} \mathrm{~S}\right)$ \\
\hline 1 & 0.05 wt.\% CMC & $100 \mathrm{rpm}$ & $0.01 \mathrm{~mL} / \mathrm{s}$ & $0.0213 \mathrm{M}$ \\
\hline 2 & 0.1 wt.\% CMC & $200 \mathrm{rpm}$ & $0.05 \mathrm{~mL} / \mathrm{s}$ & $0.0426 \mathrm{M}$ \\
\hline 3 & 0.2 wt.\% CMC & $250 \mathrm{rpm}$ & $0.15 \mathrm{~mL} / \mathrm{s}$ & $0.0639 \mathrm{M}$ \\
\hline$k_{1}$ & 64.989 & 59.867 & 59.723 & 36.892 \\
\hline$k_{2}$ & 41.132 & 40.188 & 42.693 & 49.633 \\
\hline$k_{3}$ & 29.082 & 35.149 & 32.788 & 48.678 \\
\hline$R$ & 35.907 & 24.718 & 26.935 & 12.741 \\
\hline \multicolumn{2}{|c|}{ Significance of influence } & \multicolumn{3}{|c|}{$\mathrm{A}>\mathrm{C}>\mathrm{B}>\mathrm{D}$} \\
\hline \multicolumn{2}{|c|}{ Optimal combination } & \multicolumn{3}{|c|}{$\mathrm{A}_{3} \mathrm{~B}_{3} \mathrm{C}_{3} \mathrm{D}_{1}$} \\
\hline
\end{tabular}

membrane filter of mixed cellulose esters (VSWP04700, Millipore). Control tests were carried out using 0.15 wt. $\%$ CMC solution only and all tests were conducted in duplicate.

The hydrodynamic diameter of the synthesized FeS nanoparticles was determined by Nano Zetasizer ZS90 (Malvern Instruments, UK), which is based on DLS (dynamic lighting scanning) measurement. $\mathrm{Cr}(\mathrm{VI})$ and $\mathrm{Fe}(\mathrm{II})$ in water solutions were extracted using the diphenyl hydrazine method (GB/T7467-1987, Chinese National Standards) and the $o$-phenanthroline method (HJ/T345-2007, Chinese Environmental Protection Industry Standard) and then analyzed by ultraviolet spectrophotometer (T6 PERSEE, China).

\section{Results and Discussion}

3.1. Orthogonal Array Design of FeS Nanoparticles Synthesis. The size of the nanoparticles could greatly influence the efficiency when they are utilized in environmental remediation, especially in groundwater or soil remediation. Generally, smaller nanoparticles possess higher remediation efficiency. It is well recognized that a larger surface area to volume ratio is attributed to a higher density of active reaction sites per unit mass [27]. Gong et al. [21] indicated that increasing CMC concentration resulted in smaller FeS particles, which had a greater specific surface area and more sorption sites resulting in a proved $\mathrm{Hg}^{2+}$ uptake. Hydrodynamic diameter was used for the optimization of process as the evaluation parameter. These process parameters were studied at three different levels as reported in Table 1 by $\mathrm{OA}_{9}\left(3^{4}\right)$ Orthogonal Array design. Furthermore, the average hydrodynamic diameters of products obtained in all runs of orthogonal tests are given in the last column of Table 1. As per the results shown in Table 2, the hydrodynamic diameter of synthesized particles varied with different combinations, and the significance of the synthesis conditions in descending order was as follows: stabilizer (CMC) dosage, titration speed of $\mathrm{Na}_{2} \mathrm{~S}$, oscillation rate, and initial salt $\left(\mathrm{Na}_{2} \mathrm{~S}\right)$ concentration. The optimal combination of factors was $0.2 \mathrm{wt} . \%$ CMC dosage, $250 \mathrm{rpm}$ oscillation, $0.15 \mathrm{~mL} / \mathrm{s}$ titration of $\mathrm{Na}_{2} \mathrm{~S}$ solution, and $0.0213 \mathrm{M} \mathrm{Na} \mathrm{Na}_{2} \mathrm{~S}$ concentration.

Two groups of tests were conducted to observe the influence of the foremost two important factors (stabilizer dosage and titration speed of $\mathrm{Na}_{2} \mathrm{~S}$ ) on FeS nanoparticles. Figure 2(a) depicts the particle size profile with stabilizer dosage, which shows that increasing the dosage of CMC decreased particle size significantly. When the CMC dosage increased from 0.05 wt. $\%$ to 0.15 wt. $\%$, hydrodynamic diameter declined by $110 \mathrm{~nm}$; however hydrodynamic diameter of FeS nanoparticles did not decrease significantly anymore and remained constant after the dosage above $0.15 \mathrm{wt} . \%$.

After the dosage of CMC, $\mathrm{Na}_{2} \mathrm{~S}$ titration speed is the second influential factor in the particle size [28-30]. However, it had a negligible effect on the hydrodynamic diameters of the nanoparticles, when adjusting the titration speed from 0.01 to $0.15 \mathrm{~mL} / \mathrm{s}$ as shown in Figure 2(b). 


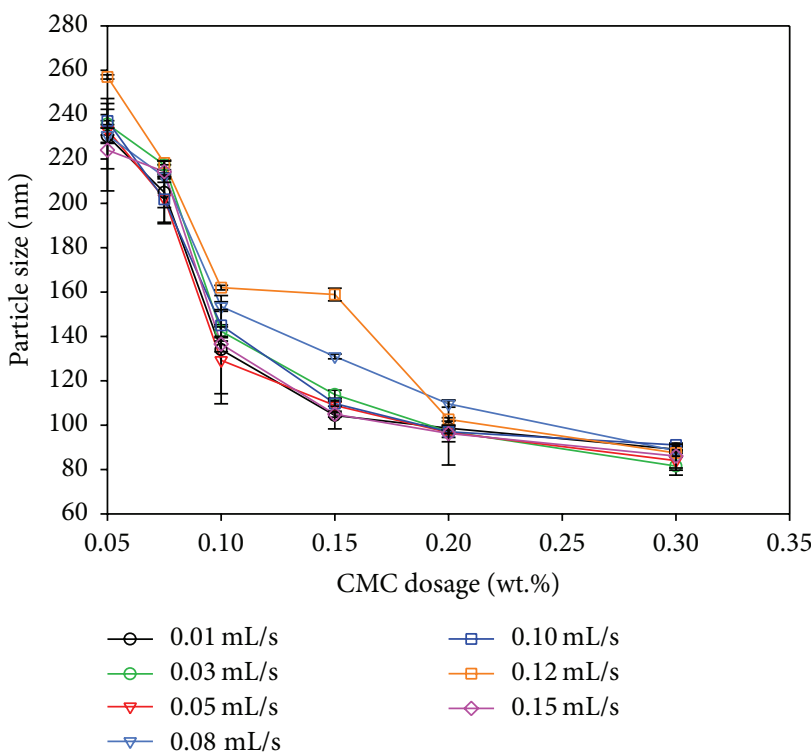

(a)

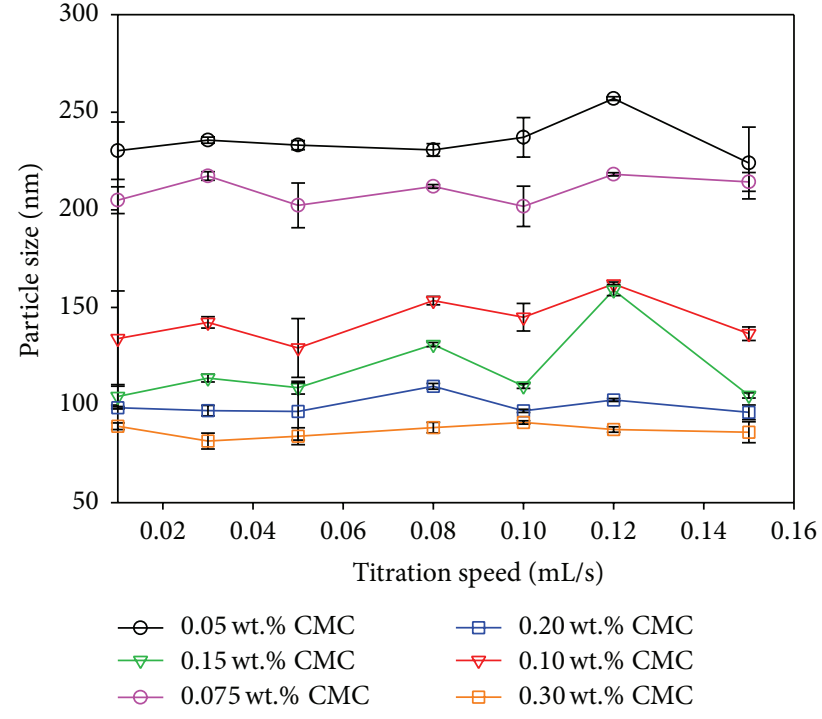

(b)

Figure 2: Particle sizes of synthesized FeS nanoparticles (a) with the dosage of $\mathrm{CMC}$ as the stabilizer and (b) with the titration speeds of $\mathrm{Na}_{2} \mathrm{~S}$ solution. Oscillation rate $=250 \mathrm{rpm}$, and $\mathrm{Na}_{2} \mathrm{~S}$ concentration $=0.0426 \mathrm{M}$. Data plotted as mean of duplicates and the error bars (calculated as standard deviation) indicate data reproducibility.

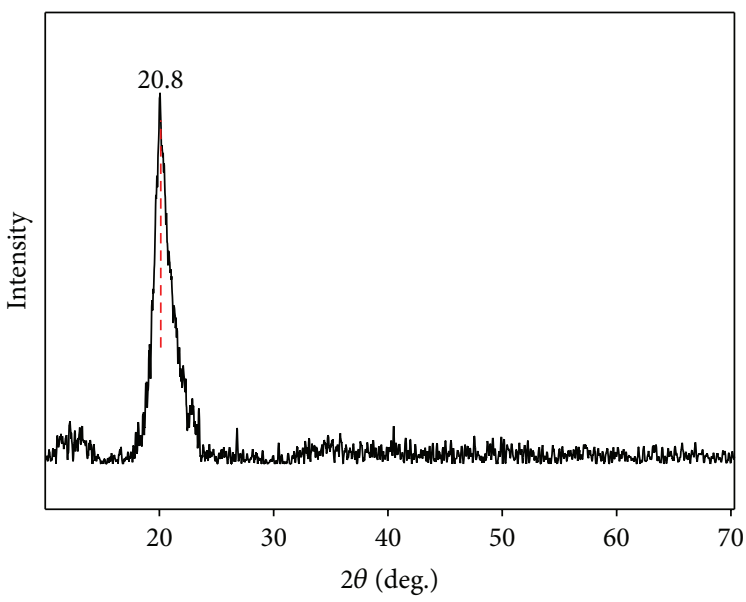

(a)

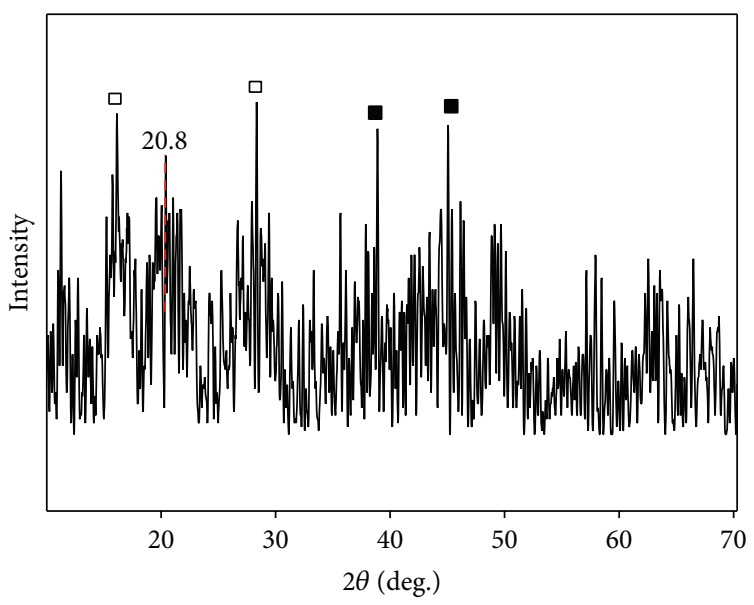

$\square \mathrm{FeS}$

- $\mathrm{Fe}_{2}\left(\mathrm{SO}_{4}\right)_{3}$

FIGURE 3: XRD patterns of (a) CMC powder and (b) synthesized FeS nanoparticles.

Our finding shows that the optimal synthesis conditions were CMC dosage at $0.15 \mathrm{wt} . \%$, oscillation rate at $250 \mathrm{rpm}$, titration speed at $0.05 \mathrm{~mL} / \mathrm{s}$, and $\mathrm{Na}_{2} \mathrm{~S}$ concentration at $0.0426 \mathrm{M}$. Under the optimal conditions, FeS nanoparticles were synthesized, characterized, and observed to check their long-term stability. Furthermore, the FeS nanoparticles were also synthesized at various stabilizer dosages under the optimal conditions and the capability of synthesized FeS nanoparticles was tested to remove $\mathrm{Cr}(\mathrm{VI})$ from aqueous solution.
3.2. Characterization of the Synthesized FeS Nanoparticles. Figure 3 shows the XRD patterns of the stabilizer CMC and the synthesized FeS nanoparticles. The diffraction peaks at around $2 \theta=17.05^{\circ}$ and $28.6^{\circ}$ correspond to the (100) and (103) planes, respectively, which attributes to the troilite FeS (ICDD 37-0477) [31]. No sharp crystalline peaks were present in the diffractograms of the synthesized FeS nanoparticles, indicating that the synthesized FeS nanoparticles had a low degree of crystallinity. Moreover, some weak diffraction peaks were present in CMC-FeS samples, which could be 


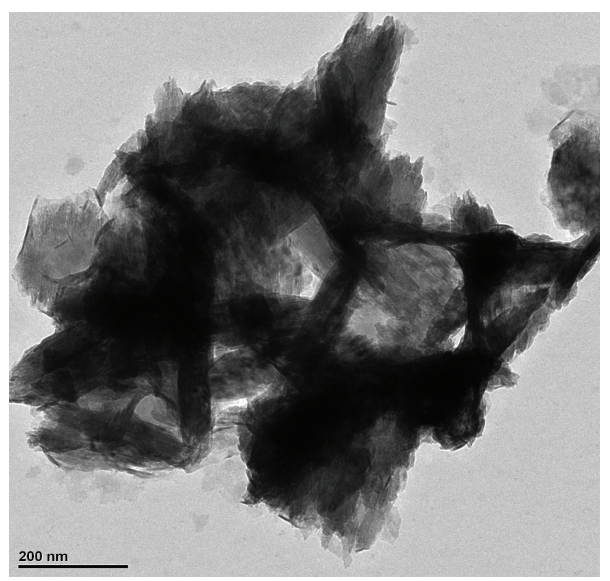

(a)

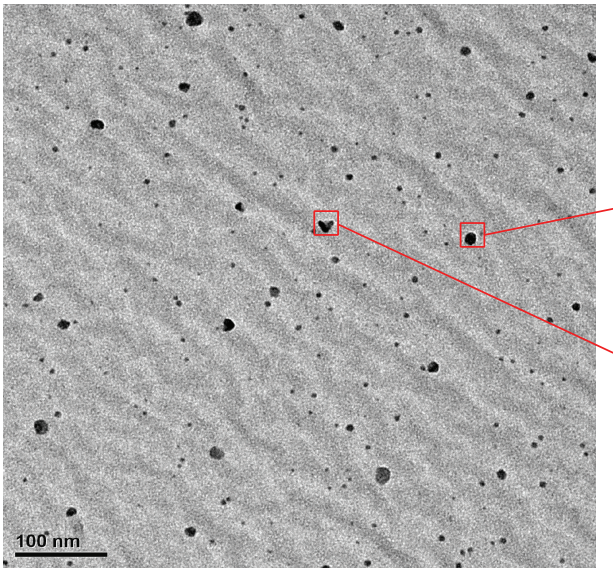

(b)

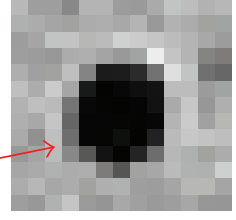

(c)

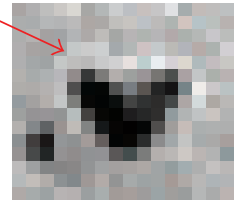

(d)

FIGURE 4: TEM images of (a) bare FeS (500 mg/L) without a stabilizer, (b) synthesized FeS nanoparticles (500 mg/L) with CMC as a stabilizer $(0.15 \mathrm{wt} . \%)$, and (c) and (d) enlarged representative nanoparticles with a shell-core structure.

attributed to the diffraction of $\mathrm{CMC}$ and $\mathrm{Fe}_{2}\left(\mathrm{SO}_{4}\right)_{3}$ in the $\mathrm{FeS}$ nanoparticles based on the material references in the ICDD database $[32,33]$. The weak diffraction peaks may be due to the poor crystallinity of the synthesized nanoparticles, which could be a result of the inhibition of the FeS crystal growth by CMC [34].

Figure 4 shows the TEM images of the bare FeS particles and the synthesized FeS nanoparticles. Without using CMC, FeS solids appeared as aggregated flocs as shown in Figure 4(a). However, CMC stabilized FeS solids were well dispersed and appeared as sphere or ellipsoid shaped particles as shown in the TEM image in Figure 4(b). CMC molecules coated on the FeS cores in Figures 4(c) and 4(d) prevented the agglomeration of particles and produced a product with a smaller size and larger surface area. Particle size of stabilized FeS products was analyzed based on the TEM images [35], and the average size of the synthesized FeS nanoparticles was $25 \pm 10 \mathrm{~nm}$.

Figure 5 shows the Fe XPS analysis of FeS nanoparticles. In the Cls spectrum of the FeS nanoparticles (Figure 5(a)), the spectrum can be deconvoluted into three individual peaks. The sharp peak at around $284.5 \mathrm{eV}$ corresponds to $\mathrm{C}=\mathrm{C}$ bonds, called $\mathrm{sp}^{2}$ carbon, while the other peaks at a higher energy come from $\mathrm{C}-\mathrm{OH}$ bonds and $\mathrm{C}=\mathrm{O}$ bonds $[36,37]$. The $\mathrm{Fe}\left(2 \mathrm{p}_{1 / 2}\right)$ peak centered at $724.8 \pm 0.4 \mathrm{eV}$ and $\mathrm{Fe}\left(2 \mathrm{p}_{3 / 2}\right)$ peak centered at $710 \pm 0.1 \mathrm{eV}$, which, respectively, belonged to $\mathrm{Fe}(\mathrm{III})-\mathrm{O}$ and $\mathrm{Fe}(\mathrm{II})-\mathrm{S}$ compounds [38]. The intensity of the peak corresponding to $\mathrm{Fe}(\mathrm{II})-\mathrm{S}$ is greater than $\mathrm{Fe}$ (III)-O, indicating that $\mathrm{Fe}(\mathrm{II})-\mathrm{S}$ is the main compound in FeS nanoparticles. Fe(III)-O may be attributed to the partial oxidation of $\mathrm{Fe}$ (II) by $\mathrm{O}_{2}$ in air or hydroxylation [39]. As Figure 5(b) shows, the $S(2 \mathrm{p})$ spectrum is dominated by features at $162.8 \pm 0.3 \mathrm{eV}$ and $161.4 \pm 0.1 \mathrm{eV}$, corresponding to polysulfide $\left(\mathrm{S}_{n}{ }^{2-}\right)$ and sulfide $\left(\mathrm{S}^{2-}\right)$ anions, respectively $[40,41]$. The $S^{2-}$ peak demonstrates the main form of sulfur in FeS nanoparticles exists as $\mathrm{S}^{2-}$ anion. However, the existence of the peaks of $\mathrm{S}_{n}{ }^{2-}$ reveals that some superficial oxidation occurred $[42,43]$.
3.3. Long-Term Stability of FeS Nanoparticles. The synthesized FeS nanoparticle was present as a suspension as shown in Figure 6 with an FeS concentration of $500 \mathrm{mg} / \mathrm{L}$. A comparative analysis of the bare FeS and CMC stabilized FeS nanoparticles was carried out in sealed glass vessels in dark condition at room temperature. Bare FeS precipitated for a period of $0.5 \mathrm{~h}$. After the storage of $24 \mathrm{~h}$, some yelloworange substances appeared on the surface of precipitates, indicating that oxidation may have occurred with the generation of ferric oxides. Moreover, the CMC stabilized FeS nanoparticles remained dispersed with similar appearance, and precipitates or yellow-orange substances were not present after 5 months, while the whole surface of bare FeS was covered with yellow-orange substances. Compared to bare FeS, CMC stabilized FeS nanoparticles showed a great stability to meet the subsequent requirements for good dispersion and mobility for the remediation of contaminated soil or groundwater.

The mean hydrodynamic diameters of $\mathrm{FeS}(0.05 \mathrm{wt} . \%$ $\mathrm{CMC}$ ) and FeS (0.15 wt.\% CMC) nanoparticles were determined at desired time intervals $(1 \mathrm{~d}, 60 \mathrm{~d}, 90 \mathrm{~d}$, and $150 \mathrm{~d}$ ). Figure 7 depicts the variation of the hydrodynamic diameters of FeS nanoparticles with the storage time. Lou [44] found that the viscosity of CMC solution reduces with time and then electrostatic attraction may get stronger than electrostatic repulsion, which may cause the increase of particle size. During the storage, particle dissolution or hydrolysis of CMC molecules may also cause the variation of the particle size [26]. However, the CMC stabilized FeS nanoparticle's hydrodynamic diameter remained approximately constant during the storage of 150 days as shown in Figure 7. Not only could CMC effectively block the particle agglomeration during the preparation stage, but also CMC coating on FeS cores may promote the dispersion of nanoparticles with the effects of electrostatic repulsion and steric hindrance [45].

Besides, the $\mathrm{Fe}(\mathrm{II})$ in water solution was determined for bare FeS and FeS nanoparticles systems, respectively. 


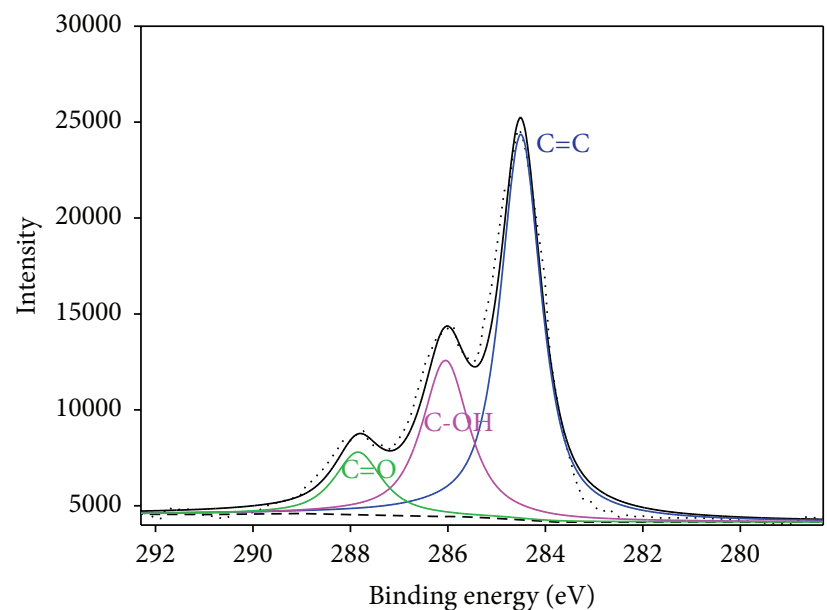

(a)

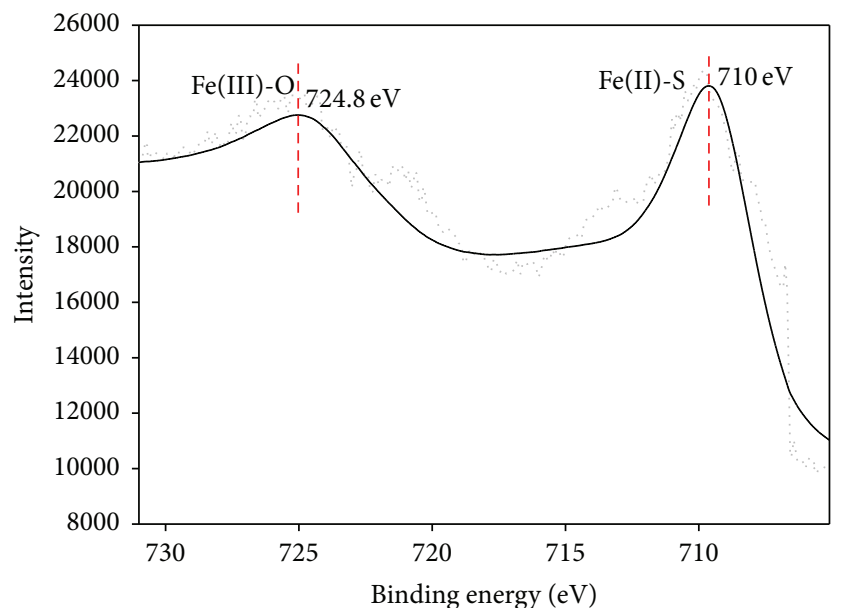

(b)

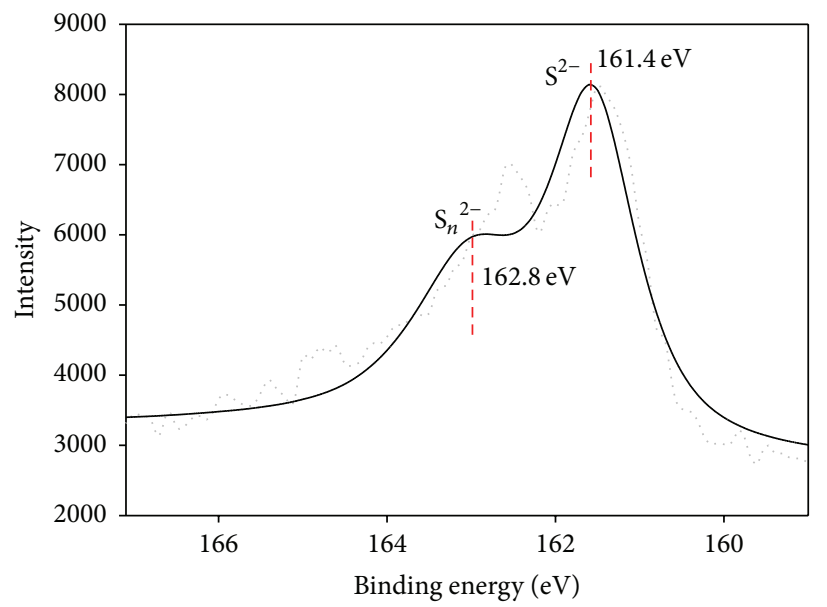

(c)

FIGURE 5: (a) C(1s), (b) Fe(2p), and (c) S(2p) X-ray photoelectron spectra of synthesized FeS nanoparticles.

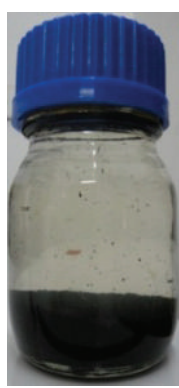

$0.5 \mathrm{~h}$

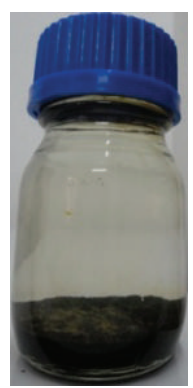

$24 \mathrm{~h}$

(a)

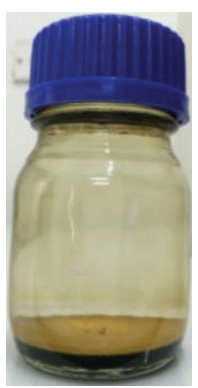

5 months

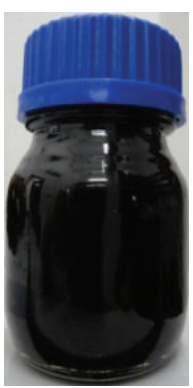

$0.5 \mathrm{~h}$

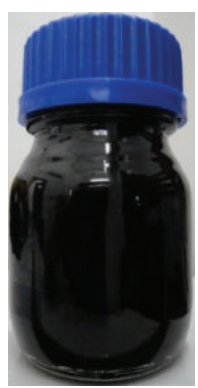

$24 \mathrm{~h}$

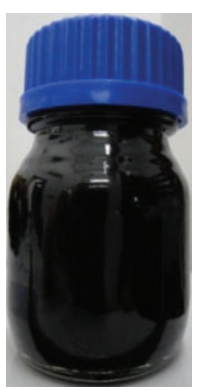

5 months

(b)

Figure 6: The long-term stability of (a) bare FeS (500 mg/L) and (b) synthesized FeS nanoparticles (500 mg/L) with CMC (0.15 wt.\%) as a stabilizer.

Figure 8 shows the aqueous Fe(II) concentration for bare $\mathrm{FeS}$ and FeS nanoparticles systems with the storage time. There was $82.17 \%$ aqueous $\mathrm{Fe}(\mathrm{II})$ left within 1 day and about $50 \%$ aqueous $\mathrm{Fe}(\mathrm{II})$ was oxidized or transferred in bare $\mathrm{FeS}$ solids, while $90 \% \mathrm{Fe}(\mathrm{II})$ still existed in CMC stabilized FeS nanoparticle system after 150 days. However, aqueous Fe(II) in the stabilized FeS nanoparticle system with different CMC dosages held a similar trend. Our data shows CMC has ability to prevent $\mathrm{Fe}$ (II) oxidation in addition to limiting the particle growth of FeS nanoparticles. 


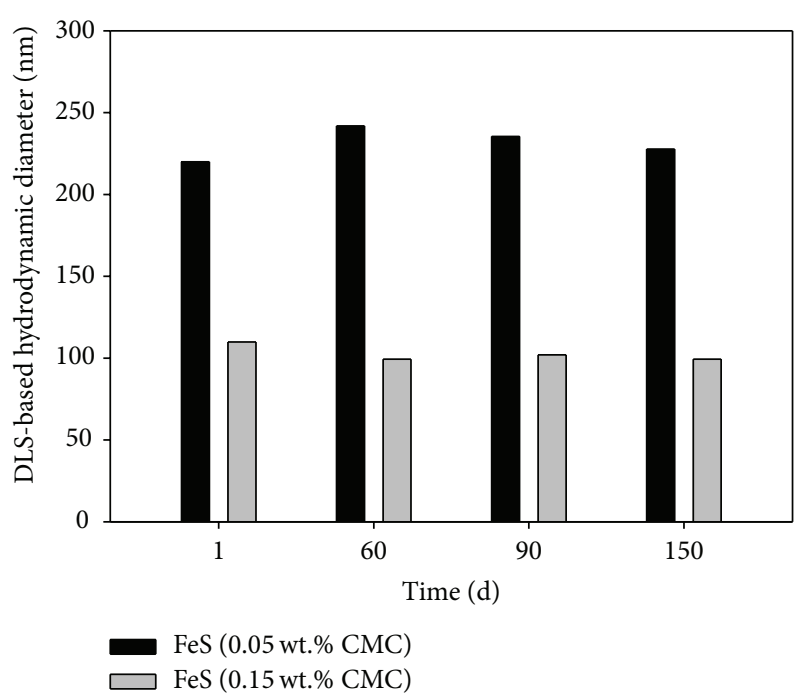

Figure 7: Hydrodynamic diameters of synthesized FeS nanoparticles with the storage time. The nanoparticles stabilized with two dosages of CMC as a stabilizer were sealed and kept in the dark at room temperature.

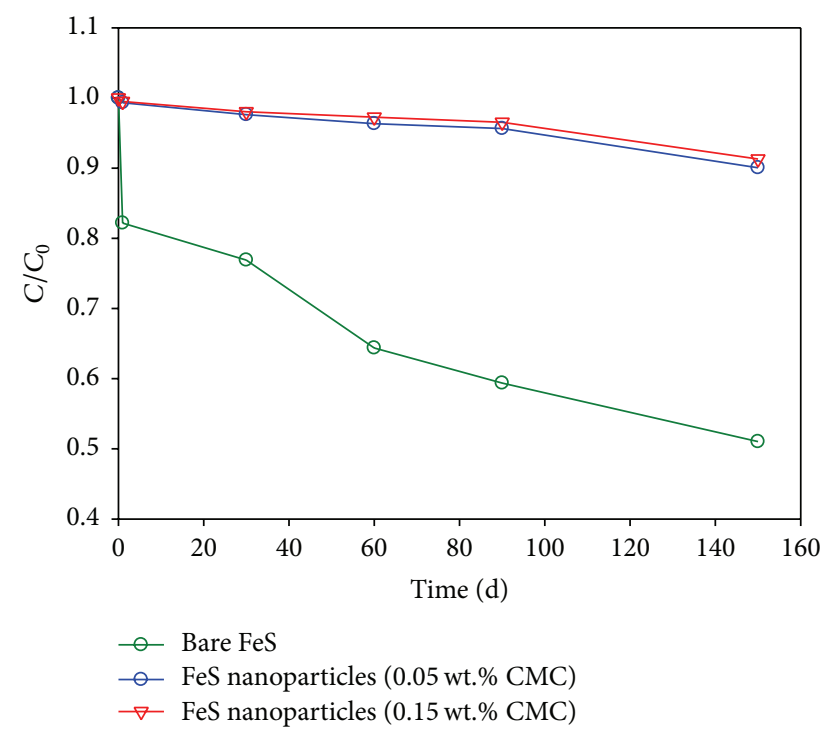

FIGURE 8: Aqueous Fe(II) concentration in bare FeS system and synthesized FeS nanoparticle suspension with the storage time.

3.4. Removal Efficiencies of Cr(VI). As observed in Figure 9, as-produced $\mathrm{FeS}$ nanoparticles achieved a higher removal efficiency of $\mathrm{Cr}(\mathrm{VI})$ than bare FeS solids during $150 \mathrm{~min}$. Higher CMC dosage during nanoparticle synthesis increased the removal efficiency, approaching $92.48 \% \mathrm{Cr}(\mathrm{VI})$ removal when the CMC dosage was increased to $0.15 \mathrm{wt} . \%$; removal of $85.30 \%$ and $81.80 \% \mathrm{Cr}(\mathrm{VI})$ was, respectively, achieved in comparison with $0.05 \mathrm{wt} . \% \mathrm{CMC}$ stabilized and bare FeS. The as-produced FeS nanoparticles removed $683 \mathrm{mg}$ per gram of $\mathrm{FeS}$ at $\mathrm{pH}$ 5.6, which has a higher capacity than those previously reported FeS materials, such as mackinawite (FeS) [46], $\mathrm{C} / \mathrm{FeS} / \mathrm{Fe}$ composite [25], and iron monosulfide (FeS) powder

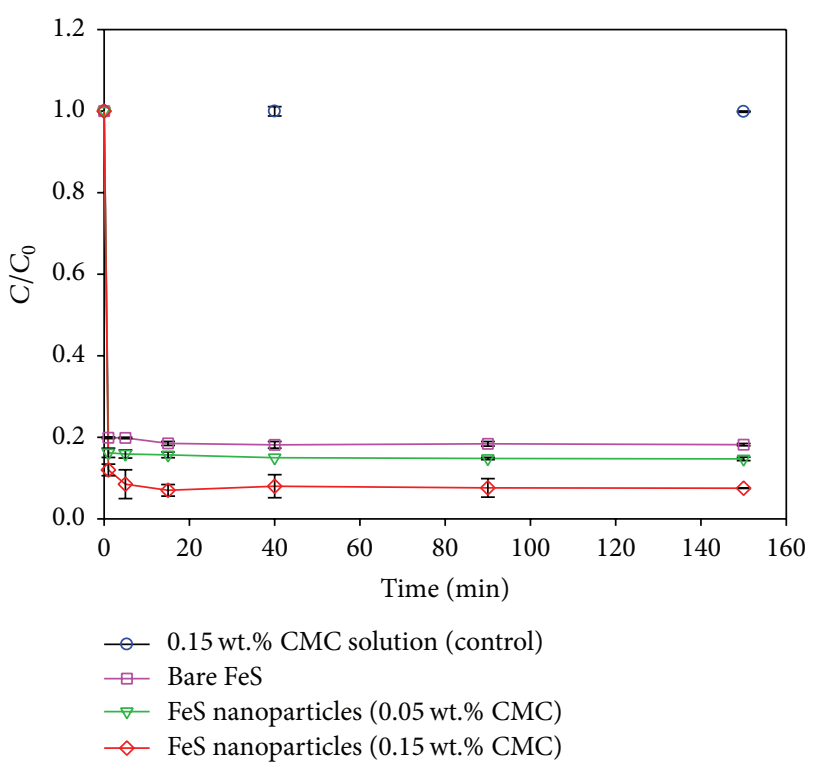

Figure 9: Removal of $\mathrm{Cr}(\mathrm{VI})$ in water solution by synthesized FeS nanoparticles. Initial $\mathrm{Cr}(\mathrm{VI})=50 \mathrm{mg} / \mathrm{L}, \mathrm{FeS}$-to-Cr(VI) molar ratio = 0.8. Data plotted as mean of duplicates and the error bars (calculated as standard deviation) indicate data reproducibility.

[47] under acidic conditions. Even compared to nanosized iron sulfide [48] with a $\mathrm{Cr}(\mathrm{VI})$ removal capacity of $506.5 \mathrm{mg}$ $\mathrm{Cr}(\mathrm{VI})$ per gram of $\mathrm{FeS}$ at initial $\mathrm{Cr}(\mathrm{VI})$ concentration of $1.56 \mathrm{~g} / \mathrm{L}$ at $\mathrm{pH} 3$, as-produced $\mathrm{FeS}$ nanoparticles removed $\mathrm{Cr}(\mathrm{VI})$ from aqueous solutions with a higher removal efficiency. Since the core materials in our nanoparticles and the above reported $[25,46,47]$ were all FeS, the higher efficiency of $\mathrm{Cr}(\mathrm{VI})$ removal by the as-synthesized FeS nanoparticles may be related to their smaller particle size and modified surface, which were produced by our optimized synthesis conditions. Moreover, hydroxyl groups in CMC molecules integrated with the $\mathrm{Fe}$ (II) to yield stable organic chelating ligands, which promote the redox reactions [49]. Therefore, CMC coated FeS nanoparticles could have the special properties of smaller size and long-term stability and possess a higher removal efficiency of $\mathrm{Cr}(\mathrm{VI})$ in water solution.

\section{Conclusions}

Hydrodynamic diameter was chosen to evaluate the synthesis parameters, which included stabilizer, time taken for titration, horizontal oscillation speed, and initial salt concentration, where Orthogonal Array design was used to make the assessment. Our data shows that the significance of the synthesis conditions was in descending order: stabilizer (CMC) dosage, titration speed of $\mathrm{Na}_{2} \mathrm{~S}$, oscillation rate, and initial salt $\left(\mathrm{Na}_{2} \mathrm{~S}\right)$ concentration, and increasing the $\mathrm{CMC}$ dosage significantly made the hydrodynamic diameter decrease between 0.05 wt. $\%$ and 0.15 wt.\% while $\mathrm{Na}_{2} \mathrm{~S}$ titration, oscillation rate, and $\mathrm{Na}_{2} \mathrm{~S}$ concentration did not show significant influence on the hydrodynamic diameter of FeS nanoparticles. 
The average size of the synthesized FeS nanoparticles was $25 \pm 10 \mathrm{~nm}$. CMC was a good stabilizer and it was coated on the surface of FeS cores. Compared to bare FeS particles (as control), as-synthesized FeS nanoparticles had a better long-term stability after 150-day storage. The synthesized FeS nanoparticles had a high Cr(VI) removal capacity of $683 \mathrm{mg}$ per gram of FeS in a short period of $15 \mathrm{~min}$, and up to $92.48 \%$ $\mathrm{Cr}(\mathrm{VI})$ was removed from water solutions.

Our optimized synthesis conditions, especially the proper dosage of CMC, resulted in the small size of $25 \pm 10 \mathrm{~nm}$ and special surface properties of CMC coating of FeS nanoparticles. The as-synthesized FeS nanoparticles possessed a higher $\mathrm{Cr}$ (VI) removal capacity comparing to the reported materials, and it could be a promising tool in the remediation of soil and groundwater contaminated by other heavy metals although the current application is $\mathrm{Cr}(\mathrm{VI})$ removal.

\section{Conflict of Interests}

The authors declare that there is no conflict of interests regarding the publication of this paper.

\section{Acknowledgments}

This research was supported by the Fundamental Research Funds for the Central Universities (Project no. 106112014CDJZR210003) and Chongqing Natural Science Foundation (Project no. cstc2014jcyjA20016).

\section{References}

[1] F. Peng, Y. Su, Y. Zhong, C. Fan, S.-T. Lee, and Y. He, "Silicon nanomaterials platform for bioimaging, biosensing, and cancer therapy," Accounts of Chemical Research, vol. 47, no. 2, pp. 612623, 2014.

[2] Y. Lu and J. W. Liu, "Catalyst-functionalized nanomaterials," Nanomedicine and Nanobiotechnology, vol. 1, no. 1, pp. 35-46, 2009.

[3] R. Sharma, K. Ragavan, M. Thakur, and K. Raghavarao, "Recent advances in nanoparticle based aptasensors for food contaminants," Biosensors and Bioelectronics, vol. 74, pp. 612-627, 2015.

[4] C. G. Granqvist, A. Azens, P. Heszler, L. B. Kish, and L. Österlund, "Nanomaterials for benign indoor environments: electrochromics for 'smart windows', sensors for air quality, and photo-catalysts for air cleaning," Solar Energy Materials and Solar Cells, vol. 91, no. 4, pp. 355-365, 2007.

[5] A. W. Carpenter, C.-F. de Lannoy, and M. R. Wiesner, "Cellulose nanomaterials in water treatment technologies," Environmental Science \& Technology, vol. 49, no. 9, pp. 5277-5287, 2015.

[6] S. Kim, T. Park, and W. Lee, "Enhanced reductive dechlorination of tetrachloroethene by nano-sized mackinawite with cyanocobalamin in a highly alkaline condition," Journal of Environmental Management, vol. 151, pp. 378-385, 2015.

[7] L. Qiu, S. Zhang, L. Zhang, M. Sun, and W. Wang, "Preparation and enhanced electrochemical properties of nano-sulfur/poly(pyrrole-co-aniline) cathode material for lithium/sulfur batteries," Electrochimica Acta, vol. 55, no. 15, pp. 4632-4636, 2010.

[8] L. Nasi, D. Calestani, T. Besagni et al., " $\mathrm{ZnS}$ and $\mathrm{ZnO}$ nanosheets from $\mathrm{ZnS}(\mathrm{en})_{0.5}$ precursor: nanoscale structure and photocatalytic properties," Journal of Physical Chemistry C, vol. 116, no. 12, pp. 6960-6965, 2012.
[9] X. D. Zhou, H. Q. Shi, B. Zhang, X. Fu, and K. Jiao, "Facile synthesis and electrochemical application of surface-modified $\mathrm{Bi}_{2} \mathrm{~S}_{3}$ urchin-like nano-spheres at room temperature," Materials Letters, vol. 62, pp. 3201-3204, 2008.

[10] Q.-S. Fu, Y.-Q. Xue, Z.-X. Cui, and M.-F. Wang, "Study on the size-dependent oxidation reaction kinetics of nanosized zinc sulfide," Journal of Nanomaterials, vol. 2014, Article ID 856489, 8 pages, 2014.

[11] L. Q. Li, Y. Yuan, Z. Y. Chen et al., “The $\mathrm{Cu}_{2} \mathrm{~S}$ nano hollow-cactus arrays: a nanostructure with a larger specific surface area and the enhanced light absorption properties," Materials Letters, vol. 108, pp. 300-303, 2013.

[12] J. G. Zhao, J. Z. Yin, and Z. H. Hua, "Synthesis, characterization and optical properties of $\mathrm{CdS}$ nanowire $/ \mathrm{SnO}_{2}$ nanoparticle nano-heterostructures," Materials Letters, vol. 122, pp. 237-239, 2014.

[13] H. Y. Jeong, J. H. Lee, and K. F. Hayes, "Characterization of synthetic nanocrystalline mackinawite: crystal structure, particle size, and specific surface area," Geochimica et Cosmochimica Acta, vol. 72, no. 2, pp. 493-505, 2008.

[14] W. B. Bai, L. F. Cai, C. X. Wu et al., "Alcohothermal synthesis of flower-like $\mathrm{ZnS}$ nano-microstructures with high visible light photocatalytic activity," Materials Letters, vol. 124, pp. 177-180, 2014.

[15] B. Liu, F. F. Wang, D. F. Zheng et al., "Hydrothermal synthesis and magnetic properties of $\mathrm{CoS}_{2}$ nano-octahedrons," Materials Letters, vol. 65, no. 17-18, pp. 2804-2807, 2011.

[16] W. Szeto, C. W. Kan, C. W. Yuen, S. Chan, and K. H. Lam, "Effective photodegradation of methyl orange using fluidized bed reactor loaded with cross-linked chitosan embedded nano-CdS photocatalyst," International Journal of Chemical Engineering, vol. 2014, Article ID 270946, 16 pages, 2014.

[17] D. R. Cummins, H. B. Russell, J. B. Jasinski, M. Menon, and M. K. Sunkara, "Iron sulfide (FeS) nanotubes using sulfurization of hematite nanowires," Nano Letters, vol. 13, no. 6, pp. 2423-2430, 2013.

[18] C. Xu, Y. Zeng, X. H. Rui et al., "Controlled soft-template synthesis of ultrathin C@FeS nanosheets with high-Li-storage performance," ACS Nano, vol. 6, no. 6, pp. 4713-4721, 2012.

[19] I. T. Sines, D. D. Vaughn II, R. Misra, E. J. Popczun, and R. E. Schaak, "Synthesis of tetragonal mackinawite-type FeS nanosheets by solvothermal crystallization," Journal of Solid State Chemistry, vol. 196, pp. 17-20, 2012.

[20] E.-J. Kim, K. Murugesan, J.-H. Kim, P. G. Tratnyek, and Y.-S. Chang, "Remediation of trichloroethylene by FeS-coated iron nanoparticles in simulated and real groundwater: effects of water chemistry," Industrial \& Engineering Chemistry Research, vol. 52, no. 27, pp. 9343-9350, 2013.

[21] Y. Y. Gong, Y. Y. Liu, Z. Xiong, and D. Y. Zhao, "Immobilization of mercury by carboxymethyl cellulose stabilized iron sulfide nanoparticles: reaction mechanisms and effects of stabilizer and water chemistry," Environmental Science and Technology, vol. 48, no. 7, pp. 3986-3994, 2014.

[22] D. Rai, L. E. Eary, and J. M. Zachara, "Environmental chemistry of chromium," Science of the Total Environment, vol. 86, no. 1-2, pp. 15-23, 1989.

[23] A. D. Henderson and A. H. Demond, "Permeability of iron sulfide (FeS)-based materials for groundwater remediation," Water Research, vol. 47, no. 3, pp. 1267-1276, 2013. 
[24] X. Wang, J. Liu, D. L. Zhao, and X. J. Song, "Preparation of CMC-stablized FeS nanoparticles and their enhanced performance for Cr(VI) removal," Advanced Materials Research, vol. 287-290, pp. 96-99, 2011.

[25] R. Yang, Y. Wang, M. Li, and Y. J. Hong, "A new carbon/ferrous sulfide/iron composite prepared by an in situ carbonization reduction method from hemp (Cannabis sativa L.) stems and its Cr(VI) removal ability," ACS Sustainable Chemistry \& Engineering, vol. 2, no. 5, pp. 1270-1279, 2014.

[26] Z. Xiong, F. He, D. Zhao, and M. O. Barnett, "Immobilization of mercury in sediment using stabilized iron sulfide nanoparticles," Water Research, vol. 43, no. 20, pp. 5171-5179, 2009.

[27] S. J. Tesh and T. B. Scott, "Nano-composites for water remediation: a review," Advanced Materials, vol. 26, pp. 6056-6068, 2014.

[28] P. Stén and W. Forsling, "Precipitation of lead sulfide for surface chemical studies," Colloids \& Surfaces A: Physicochemical and Engineering Aspects, vol. 172, no. 1-3, pp. 17-31, 2000.

[29] Y. Wang, Z. Li, and G. P. Demopoulos, "Controlled precipitation of nesquehonite $\left(\mathrm{MgCO}_{3} \cdot 3 \mathrm{H}_{2} \mathrm{O}\right)$ by the reaction of $\mathrm{MgCl}_{2}$ with $\left(\mathrm{NH}_{4}\right)_{2} \mathrm{CO}_{3}$," Journal of Crystal Growth, vol. 310, no. 6, pp. 12201227, 2008 .

[30] C. Yao, Y. H. Zhang, J. Chen, D. X. Bao, S. Li, and G. W. Qin, “Size controlled preparation of Fe-B-P submicrometre particles and magnetic performance," Materials Research Innovations, vol. 18, no. 4, pp. S4634-S4638, 2014.

[31] E. B. Shangguan, F. Li, J. Li et al., "FeS/C composite as highperformance anode material for alkaline nickel-iron rechargeable batteries," Journal of Power Sources, vol. 291, pp. 29-39, 2015.

[32] M. L. S. Oliveira, C. R. Ward, M. Izquierdo et al., "Chemical composition and minerals in pyrite ash of an abandoned sulphuric acid production plant," Science of the Total Environment, vol. 430, pp. 34-47, 2012.

[33] A. K. Dutta, S. K. Maji, D. N. Srivastava et al., "Synthesis of FeS and FeSe nanoparticles from a single source precursor: a study of their photocatalytic activity, peroxidase-like behavior, and electrochemical sensing of $\mathrm{H}_{2} \mathrm{O}_{2}$," ACS Applied Materials \& Interfaces, vol. 4, no. 4, pp. 1919-1927, 2012.

[34] Y. Y. Gong, Y. Y. Liu, Z. Xiong, D. Kaback, and D. Y. Zhao, "Immobilization of mercury in field soil and sediment using carboxymethyl cellulose stabilized iron sulfide nanoparticles," Nanotechnology, vol. 23, no. 29, pp. 294-301, 2012.

[35] F. He and D. Y. Zhao, "Manipulating the size and dispersibility of zerovalent iron nanoparticles by use of carboxymethyl cellulose stabilizers," Environmental Science \& Technology, vol. 41, no. 17, pp. 6216-6221, 2007.

[36] L. Wang, S. Dou, J. Xu et al., "Highly nitrogen doped carbon nanosheets as an efficient electrocatalyst for the oxygen reduction reaction," Chemical Communications, vol. 51, no. 59, pp. 11791-11794, 2015.

[37] B. Li, D. S. Geng, X. J. S. Lee et al., "Eggplant-derived microporous carbon sheets: towards mass production of efficient bifunctional oxygen electrocatalysts at low cost for rechargeable Zn-air batteries," Chemical Communications, vol. 51, no. 42, pp. 8841-8844, 2015.

[38] J. Hu, G. Chen, and I. M. C. Lo, "Removal and recovery of $\mathrm{Cr}(\mathrm{VI})$ from wastewater by maghemite nanoparticles," Water Research, vol. 39, no. 18, pp. 4528-4536, 2005.

[39] M. Mullet, V. Khare, and C. Ruby, "XPS study of Fe(II)-Fe(III) (oxy)hydroxycarbonate green rust compounds," Surface \& Interface Analysis, vol. 40, no. 3-4, pp. 323-328, 2008.
[40] E.-J. Kim, J.-H. Kim, A.-M. Azad, and Y.-S. Chang, "Facile synthesis and characterization of Fe/FeS nanoparticles for environmental applications," ACS Applied Materials \& Interfaces, vol. 3, no. 5, pp. 1457-1462, 2011.

[41] C. D. Wagner, W. M. Riggs, L. E. Davis, J. F. Moulder, and G. E. Muilenberg, Handbook of X-Ray Photoelectron Spectroscopy, Perkin Elmer Corporation, Physical Electronics Division, Eden Prairie, Minn, USA, 1979.

[42] H. W. Nesbitt and I. J. Muir, "X-ray photoelectron spectroscopic study of a pristine pyrite surface reacted with water vapour and air," Geochimica et Cosmochimica Acta, vol. 58, no. 21, pp. 46674679, 1994.

[43] P. R. Holmes and F. K. Crundwell, "Polysulfides do not cause passivation: results from the dissolution of pyrite and implications for other sulfide minerals," Hydrometallurgy, vol. 139, pp. 101-110, 2013.

[44] Y. M. Lou, "The viscosity of CMC solution and its determination," Journal of Textile Research, vol. 3, no. 4, pp. 229-231, 1982 (Chinese).

[45] H. J. Qian, The reduction of $\mathrm{Cr}(\mathrm{VI})$ in contaminated water using CMC-stabilized zero valent iron nanoparticles [M.S. thesis], Zhejiang University, Hangzhou, China, 2008 (Chinese).

[46] M. Mullet, S. Boursiquot, and J.-J. Ehrhardt, "Removal of hexavalent chromium from solutions by mackinawite, tetragonal FeS," Colloids \& Surfaces A: Physicochemical and Engineering Aspects, vol. 244, no. 1-3, pp. 77-85, 2004.

[47] S. Jo, J. Y. Lee, S.-H. Kong, J. Choi, and J.-W. Park, "Iron monosulfide as a scavenger for dissolved hexavalent chromium and cadmium," Environmental Technology, vol. 29, no. 9, pp. 975983, 2008.

[48] Y.-F. Xie, X.-D. Li, and F.-D. Li, "Property analysis of nanosized iron sulfide produced by sulfate reducing bacteria and its application in the treatment of wastewater containing high concentration of $\mathrm{Cr}(\mathrm{VI})$," Environmental Science, vol. 30, no. 4, pp. 1060-1065, 2009 (Chinese).

[49] B. Deng, D. R. Burris, and T. J. Campbell, "Reduction of vinyl chloride in metallic iron-water systems," Environmental Science \& Technology, vol. 33, no. 15, pp. 2651-2656, 1999. 

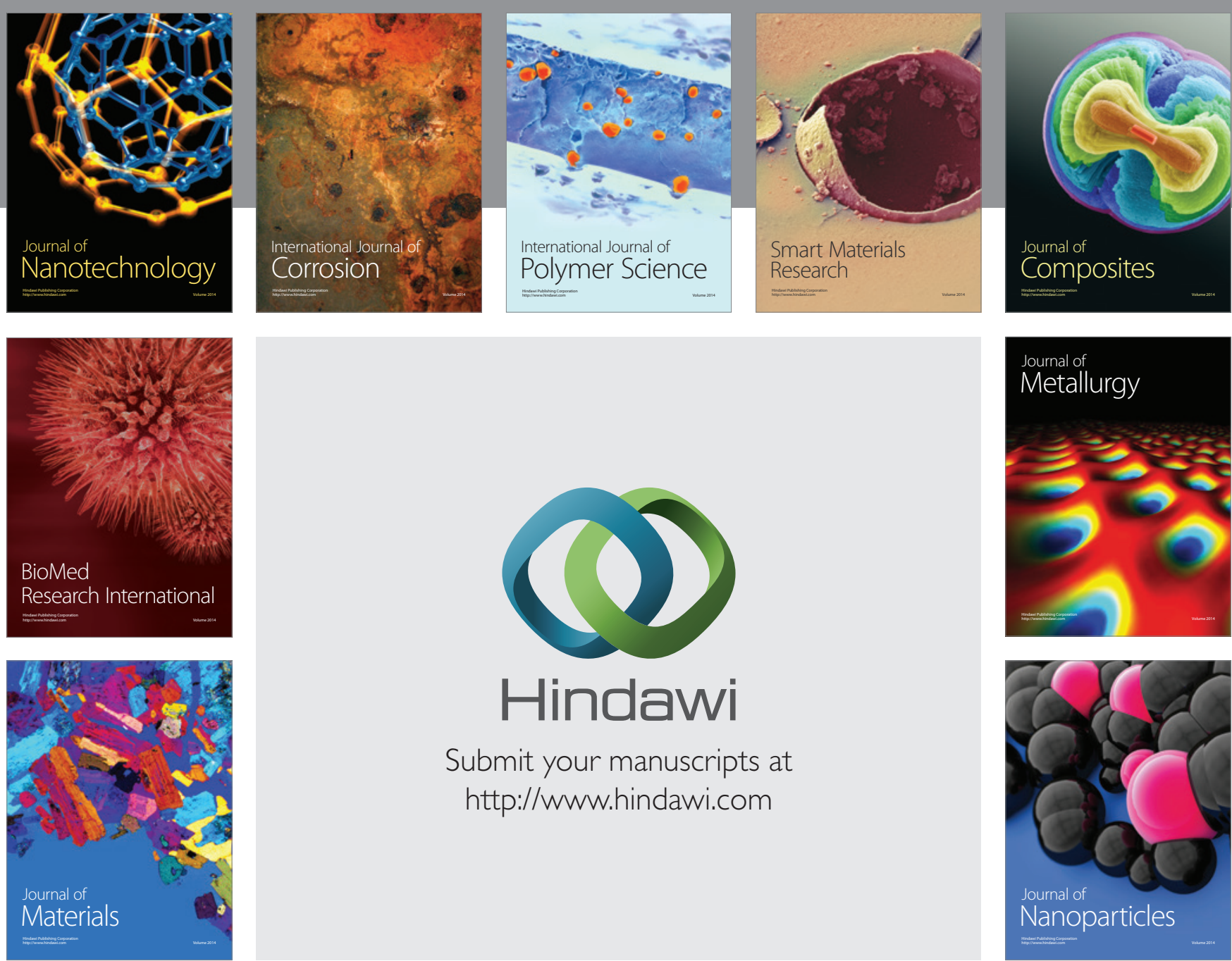

\section{Hindawi}

Submit your manuscripts at

http://www.hindawi.com

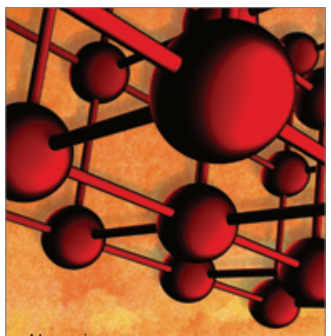

Materials Science and Engineering
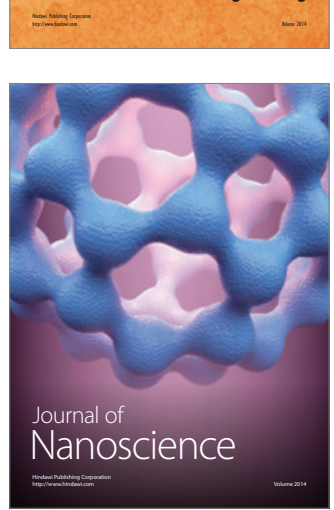
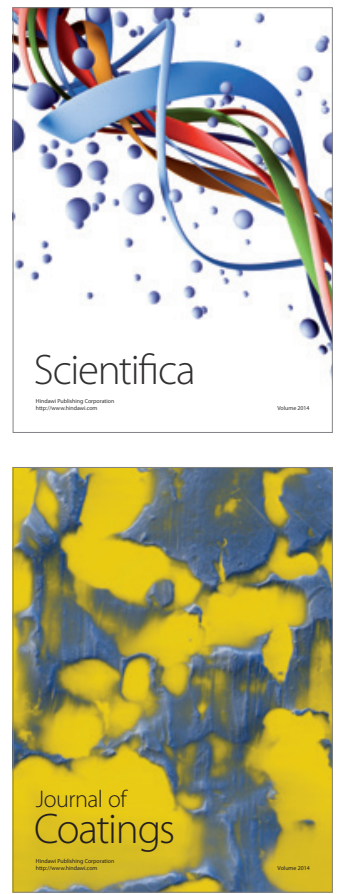
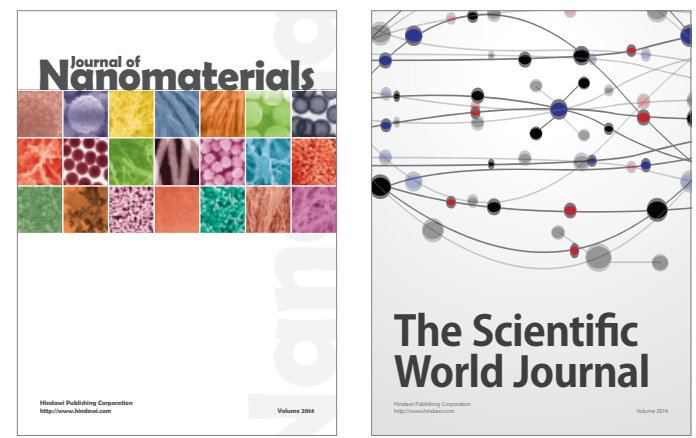

The Scientific World Journal
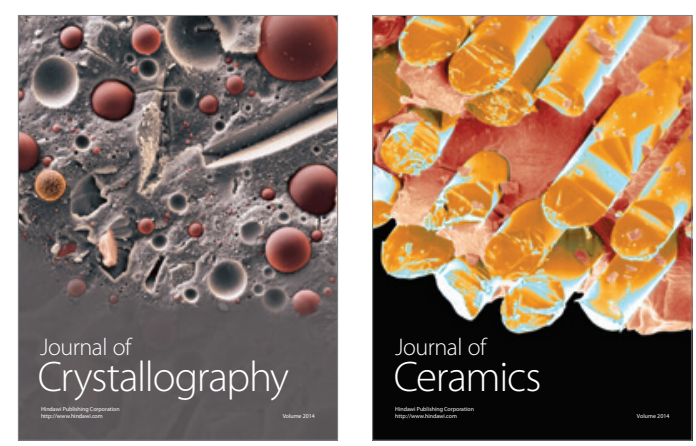
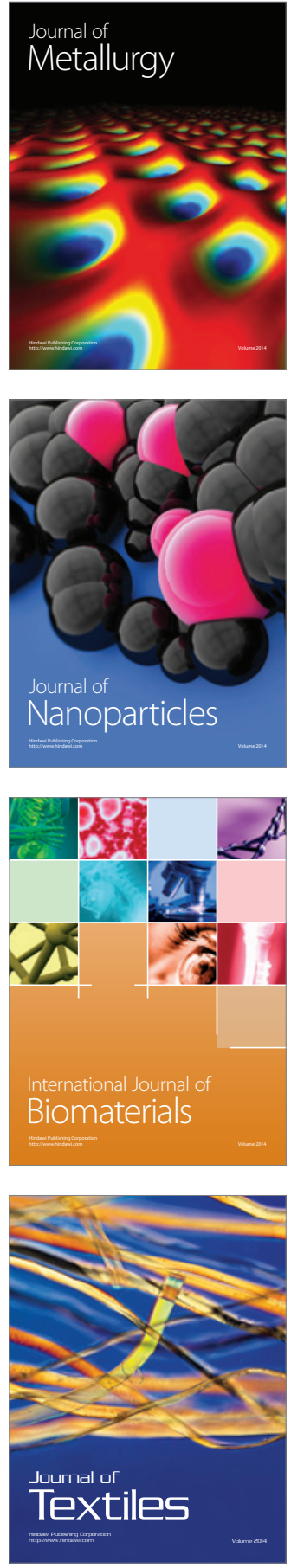